\title{
Comprehensive Effects of Temperature, Salinity, and Current Velocity on the Microplastic Abundance in Offshore Area
}

\author{
Jin Liü, Haiyang Liu*, Dongyang He, Tingting Zhang, Jiao Qu*, \\ Yihan Lv, Ya-nan Zhang**
}

School of Environment, Northeast Normal University, NO. 2555 Jingyue Street, Changchun, Jilin 130117, China

Received: 22 March 2021

Accepted: 18 September 2021

\begin{abstract}
Three offshore areas including the East China Sea, Java Island in Indonesia, and Tampa Bay in the USA were selected as the survey regions. The effects of hydrological conditions on the abundance of microplastic in the survey marine regions were analyzed using the multiple linear regression analysis in this work. The regression models were constructed with the seawater temperature, salinity, and current velocity as independent variables. The models showed that current velocity was the most important factor that affected the accumulation or diffusion of microplastic. Seawater temperature and salinity also affected microplastic abundance by affecting the movement and density of seawater. It is feasible to establish a regression model of microplastic abundance through hydrological data in offshore areas to analyze and predict the migration and accumulation characteristics of microplastic. The interaction of hydrological factors determined the abundance of marine microplastic.
\end{abstract}

Keywords: regression model, microplastic, abundance, hydrological condition, seawater

\section{Introduction}

The scientific community's research and attention on marine plastic pollution already begun in the 1970 s but the concept of microplastic was not first proposed until 2004. [1-4] The diameter of plastic fragments in the ocean ranged from a few centimeters to nanometers. Plastic fragments with a diameter of less than $5 \mathrm{~mm}$ are generally named as microplastic, and some studies

\footnotetext{
\#These authors contributed to the work equally and should be regarded as co-first authors.

*e-mail: quj100@nenu.edu.cn

**e-mail: zhangyn912@nenu.edu.cn
}

suggested that plastic fragments with a diameter of less than $1 \mathrm{~mm}$ were referred to as microplastic [5].

Since the concept of microplastic pollution was proposed, society and academia have paid more and more attention to this new type of pollutant, and the issue of microplastic pollution in the marine environment has also received increasing attention [6]. The distribution of microplastic in the marine environment was extensive. Microplastic have been detected in remote areas with little or no human activity, for instance, the content of microplastic in the groundwater of the Arctic Central Basin was $0.7 \mathrm{n} \mathrm{m}^{-3}$ [7]. The content of microplastic in sea ice of eastern Antarctica reached up to $11.71 \mathrm{n} \mathrm{L}^{-1}$ [8]. In addition, there were some 
investigations and reports on microplastic in areas with frequent human activities. The content of microplastic in the surface water of the San Francisco Bay was $0.7 \mathrm{n} \mathrm{m}^{-2}$ [9]. The detected mean contents of microplastic in the sediments of the Bohai Sea, North Yellow Sea, and South Yellow Sea in China were 171.8, 123.6, and $72.0 \mathrm{n} \mathrm{kg}^{-1}$, respectively [10].

There were many sources of microplastic in marine environment, and terrestrial input was one of the most important ways [11]. The runoff input from the land was the main source of marine microplastic, accounting for $80 \%$ of the total microplastic in the sea [12]. Wastewater from sewage treatment plants also contained a great number of microplastic fragments [13]. Furthermore, the distribution and accumulation of marine microplastic were also affected by other factors. Extreme weather (such as typhoons) would increase the accumulation of microplastic on the surface of seawater [14]. There was a positive correlation between the chlorophyll content of seawater and microplastic abundance [15]. The vortex increased microplastic pollution in the surface water of the Nordic Sea [16]. The content of microplastic was likely to accumulate in areas due to the biological accumulation of microplastic, such as mussels [17].
In recent years, a substantial number of reports concluded that multiple factors, such as physical oceanography, distance to land, source inputs, played complex and collective roles in the marine microplastic distribution [18-19]. The factors influencing microplastic abundance in an area were complex and diverse, but which had some certain commonalities. In this work, detailed microplastic abundance data and accurate hydrological information were collected from three different sea areas, including the East China Sea, northern Surabaya in East Java, and Tampa Bay in Florida. According to statistical methods, the multiple linear regression models were established with microplastic abundance as the dependent variable and constructed with the seawater temperature, salinity, and current velocity as independent variables. This study aimed to build the mathematical model and explore the comprehensive impact of some hydrological conditions such as temperature, salinity, and current velocity on regional microplastic abundance by using statistical methods. It was of great significance for the study of micro plastic pollution by summarizing the characteristics of regional influencing factors through model study.
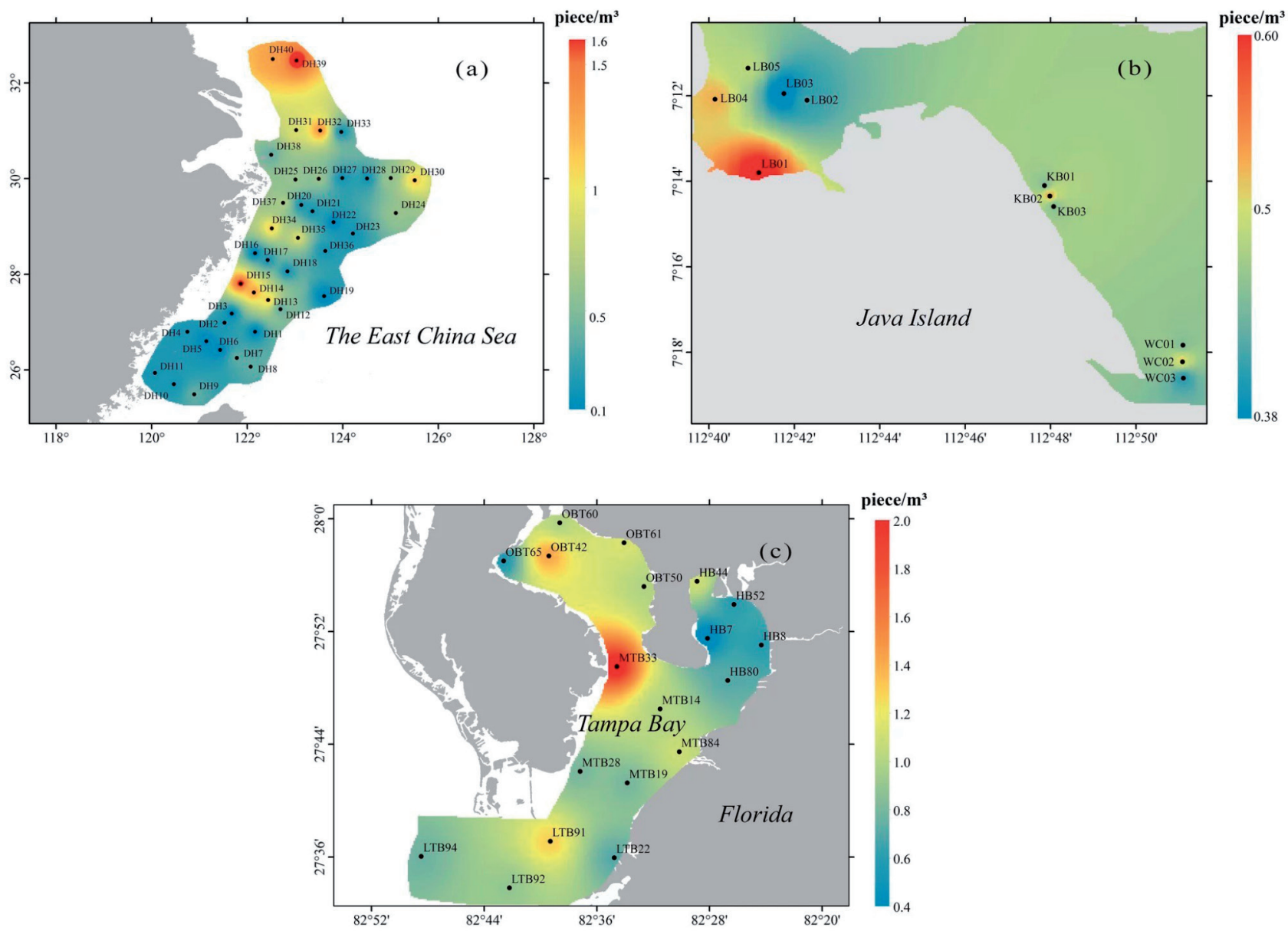

Fig. 1. Distribution of sampling points and microplastic abundance in the three areas. a) was the East China Sea, b) was the North Surabaya in East Java of Indonesia, c) was the Tampa Bay in Florida of USA. Note: Distribution of sampling points and microplastic abundance in the three areas. a) was the East China Sea, b) was the North Surabaya in East Java of Indonesia, c) was the Tampa Bay in Florida of USA. 
Table 1. Sampling time and number of sites.

\begin{tabular}{|c|c|c|}
\hline Survey marine region & Sampling time & Number of sites \\
\hline Area A & August 2015 & 40 \\
\hline Area B & March 2017 & 11 \\
\hline Area C & August 2018 & 19 \\
\hline
\end{tabular}

\section{Material and Methods}

\section{Area Description}

The sampling time of microplastic abundance data and hydrological information ranged from 2015 to 2018 . The selected three offshore areas, where the microplastic abundance studies had been conducted, were located in the East China Sea (Area A), North Surabaya in East Java of Indonesia (Area B), and Tampa Bay in Florida of USA (Area C). Area A was an open ocean area, area $\mathrm{B}$ and area $\mathrm{C}$ were relatively closed straits or bay areas. The sampling areas and points were shown in Fig. 1 and the sampling time and the number of points in the three areas were shown in Table 1.

These three regions have conducted relevant research on microplastic pollution and have detailed data on the abundance of microplastic; the hydrological data in the region were true and reliable, with continuity in time and breadth in space; these regions were all offshore areas; Sampling time should be roughly the same in season, all belonged to the rainy season.

\section{Data Collection}

Microplastic abundance data, including latitude and longitude of sampling points, and microplastic abundances were mainly obtained from Liu et al. study of the East China Sea, Cordova et al. work in Indonesia, and McEachern et al. report of Tampa Bay in Florida [20-22]. The statistical unit of microplastic abundance was pieces $/ \mathrm{m}^{-3}$. The samples of microplastic came from surface seawater at a depth of 2-5 m. The sample collection used a plankton net with a mesh diameter of 50-60 cm and a sieve aperture of $330-500 \mu \mathrm{m}$. Deployed the plankton net on the vessel and towed at a constant speed in the horizontal direction. The collected samples were kept frozen before being sent to the laboratory. The samples were rinsed with deionized water in the laboratory, and the microplastic particles were manually counted under a microscope. This was the common feature of sample collection in the three different regions, which was to minimize the impact of the differences in the collection process on the microplastic data.

The main sources of hydrological data were collected from China's Argo Real-Time Data Center, GFS (Global Forecasting System), and NCEP (National Centers for Environmental Prediction). The main purpose was to screen out the marine hydrological information on the sampling day at the microplastic sampling points. The selected hydrological information included seawater temperature, salinity, and current velocity. The collected hydrological information was consistent in each sampling point [23-24].

\section{Model and Verification}

The multiple linear regression models were constructed microplastic abundance (used as dependent variable) with seawater temperature, salinity, and current velocity in three areas as independent variables. In addition, SPSS22 software was used to model and verify the reliability and accuracy of the multiple linear regression models and the linear relationships between independent variables and dependent variables.

\section{Results and Discussion}

Results

\section{Modeling Results}

The temperature of seawater in three sea areas ranged from 26.00 to $28.90^{\circ} \mathrm{C}$. The range of salinity was $32.145-34.500 \%$ and ocean current velocity was 0.05-0.80 $\mathrm{m} \mathrm{s}^{-1}$. The modeling tool was SPSS22, and the modeling results were shown in Table 2 . The results indicated that the regression coefficients were statistically significant at the test level $<0.05$.

Table 2. Modeling results for three areas.

\begin{tabular}{|c|c|c|}
\hline Survey marine region & Modeling results & Sig. \\
\hline Area A & $\mathrm{a}=19.714-0.326 \mathrm{t}-0.298 \mathrm{~s}-0.600 \mathrm{v}$ & .001 \\
\hline Area B & $\mathrm{a}=3.328-0.052 \mathrm{t}-0.042 \mathrm{~s}-0.083 \mathrm{v}$ & .001 \\
\hline Area C & $\mathrm{a}=3.130-0.045 \mathrm{t}-0.041 \mathrm{~s}-0.100 \mathrm{v}$ & .001 \\
\hline
\end{tabular}

Note: a represented abundance of microplastic, $t$ represented seawater temperature, $\mathrm{s}$ represented salinity of seawater, and $\mathrm{v}$ represented current velocity. All significance level values of $\mathrm{t}$ test, corresponding to temperature, salinity, and current velocity, were less than 0.05 . 
Table 3. Correlation analysis results.

\begin{tabular}{|c|c|c|c|}
\hline Survey marine region & Temperature & Salinity & Current velocity \\
\hline Area A & $-0.560^{* * *}$ & $-0.385^{* *}$ & $-0.505^{*}$ \\
\hline Area B & $-0.876^{* *}$ & $-0.822^{* *}$ & $-0.914^{* *}$ \\
\hline Area C & $-0.849^{* *}$ & $-0.778^{* *}$ & $-0.918^{* *}$ \\
\hline
\end{tabular}

Note: values in the table were correlation coefficients between independent variables and microplastic abundance. $p$ was the significance level, ${ }^{*}$ was $\mathrm{p}<0.05,{ }^{*}$ was $\mathrm{p}<0.01$, and $* * *$ was $\mathrm{p}<0.001$

\section{Model Validation}

The dependent variables were normally distributed, the dependent variables were independent from each other, and the variance was homogeneous. Pearson correlation coefficient was used, and the results of the correlation analysis were shown in Table 3 . When correlation coefficients were equal to 0 in statistical research and analysis, the two variables were uncorrelated. The results of correlation analysis showed that the absolute values of all correlation coefficients were greater than 0 , which meant that correlations among the seawater temperature, salinity, current velocity, and the microplastic abundance were related.

As shown in Fig. 2, the results of the normal distribution hypothesis test were represented by P-P (probability-probability) plots. P-P plots were based on

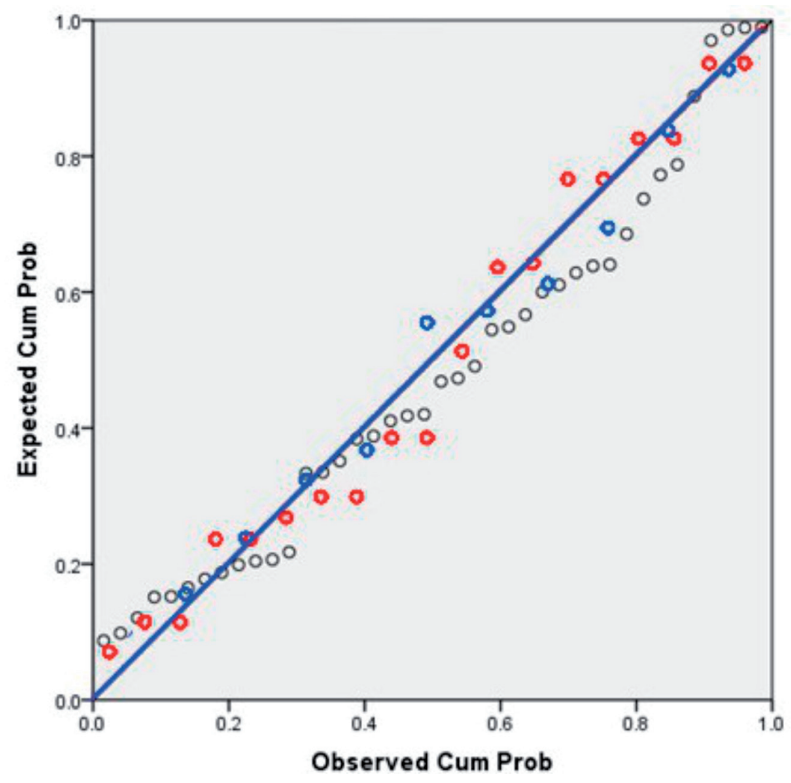

Fig. 2. P-P chart of three sets of data. Black indicated area A; blue indicated area $\mathrm{B}$; and red indicated area $\mathrm{C}$. The $\mathrm{x}$-axis represented the cumulative proportion of actual data, and the y-axis represented the cumulative proportion of normal distribution of the corresponding data. Note: P-P chart of three sets of data. Black indicated area A; blue indicated area $\mathrm{B}$; and red indicated area $\mathrm{C}$. The $\mathrm{x}$-axis represented the cumulative proportion of actual data, and the y-axis represented the cumulative proportion of normal distribution of the corresponding data. the relationship between the cumulative proportions of a variable and a specified distribution. P-P plots were usually used to verify whether the data were normally distributed. The results of the hypothesis test for the normal distribution of the dependent variable verified that the dependent variable of the model conformed to the normal distribution. Furthermore, the points in Fig. 2 were located near the straight line and evenly distributed on both sides of the straight line. It verified that the residuals of the dependent variable conformed to the normal distribution.

The results of variance inflation factor (VIF) test were shown in Table 4, which meant that there was no multicollinearity between dependent variables. VIF is a measure of the severity of multicollinearity in a multiple linear regression model. It represents the ratio of the variance of the regression coefficient estimator to the variance assuming that the independent variables are not linearly correlated. It was generally considered that there was no multicollinearity when the VIF values of dependent variables were all less than 10 [25]. Therefore, the independent variables of the model were independent of each other.

The results of the ANOVA (Analysis of Variance) test were shown in Table 5. The ANOVA test, also known as the $\mathrm{F}$ test, was usually used to test the significance of the difference between two or more samples. The results of variance analysis confirmed the homogeneity of the model. All sig. values of the ANOVA test in the three areas passed the test with a significance level of 0.05 and the reliability test of multiple linear regression. The results meant that the variances of the three models were homogeneous, accurate, and reasonable.

Table 4. VIF test results.

\begin{tabular}{|c|c|c|c|}
\hline $\begin{array}{c}\text { Survey } \\
\text { marine region }\end{array}$ & $\mathrm{VIF}_{\mathrm{t}}$ & $\mathrm{VIF}_{\mathrm{s}}$ & $\mathrm{VIF}_{\mathrm{v}}$ \\
\hline Area A & 1.032 & 1.087 & 1.120 \\
\hline Area B & 4.727 & 1.574 & 5.379 \\
\hline Area C & 3.626 & 1.511 & 4.257 \\
\hline
\end{tabular}

Note: VIF, represented VIF of the independent variable temperature, VIF represented VIF of the independent variable salinity, and VIF represented VIF of the independent current velocity. 
Table 5. ANOVA test results of three models.

\begin{tabular}{|c|c|c|}
\hline Survey marine region & $\mathrm{F}$ & Sig. \\
\hline Area A & 14.171 & .001 \\
\hline Area B & 83.447 & .001 \\
\hline Area C & 105.682 & .001 \\
\hline
\end{tabular}

Note: F values were the ratio of two variances or two mean squares, Sig. Values represented significance.

Table 6. Goodness of fit of the three models.

\begin{tabular}{|c|c|c|}
\hline Survey marine region & $\mathrm{R}^{2}$ & Sig. \\
\hline Area A & .541 & .001 \\
\hline Area B & .973 & .001 \\
\hline Area C & .955 & .001 \\
\hline
\end{tabular}

\section{Goodness of Fit}

The goodness of fit referred to the degree of fit for the regression line to the observed values. The coefficient of determination $\left(\mathrm{R}^{2}\right)$ was used to measure the goodness of fit. The $\mathrm{R}^{2}$ of the three areas model was shown in Table 6. The goodness on the fit of the three models all passed the test with a significance level of 0.05 .

\section{Discussion}

\section{Influence of Temperature on Microplastic Abundance}

In the previous reports on the characteristics of microplastic, the possible impact of temperature in the water environment on microplastic abundance was always ignored. For example, in the studies of microplastic in San Francisco Bay, California, factors on microplastic abundance such as anthropogenic discharge along the coast and estuary input accumulation were considered in the work [9]. However, the hydrological conditions were ignored.

From the three areas, microplastic abundance in the sampling points closer to the estuary (DH3, DH4, DH11, DH16, DH38, WC03, LB03, HB7, HB8, HB52, LTB22, and OBT65) was relatively low. As shown in Fig. 1, the sampling points (DH15, DH32, DH39, OTB42, and MTB33) under the influence of the same current had high abundance values. The sampling time was period with the higher temperature (shown in Table 1). The specific heat capacity of land was smaller than that of the ocean, so the temperature of surface runoff was higher than that of seawater. Therefore, the temperature of the seawater at the sampling point near the estuary was relatively high. The seawater temperature would gradually decrease as the current moved away from the estuary area. In this process, the velocity of current would decrease, so the diffusion rate of microplastic particles became slower and microplastic abundance increased. This might be the reason why microplastic abundance was significantly negatively correlated with seawater temperature (shown in Table 3).

The study of Goa coast in India showed that the distribution of microplastic abundance was seasonal [26]. The area was affected by the southwest monsoon in June, and microplastic abundance was significantly higher than the level in January of the same year. The microplastic particles could accumulate under conductive hydrodynamic conditions. High-temperature summer was the season of strong monsoon activity. Precipitation and current activities caused by monsoon could transport more microplastic to coastal areas. This was of great significance to the study of the mechanism of temperature in the coastal area on the abundance of microplastic in Fig. 1.

In areas far from land, the effect of seawater temperature on microplastic abundance was relatively insignificant. From the correlation coefficient between the temperature and microplastic abundance, the correlation coefficients of areas $\mathrm{B}$ and $\mathrm{C}$ were similar (-0.876 and -0.849). The correlation coefficient of area A was relatively low (-0.560) (shown in Table 3). It might be caused by the difference in the number of sampling points and the distribution of locations. The sampling points of area A were more than other areas, and most of the points were far away from the coastal areas. The microplastic in these points were partly from surface runoff and partly from ocean current transport. The seawater temperature at these locations would be affected by cold or warm currents, and the water temperature in two areas at the same latitude might be quite different. For these reasons, the correlation coefficient of area A was low (-0.560). The sampling points in areas $\mathrm{B}$ and $\mathrm{C}$ were less and mostly located in the coastal or estuary area. The seawater temperature in these areas was relatively stable due to surface runoff temperature and latitude. Hence, the correlation coefficients $(-0.876$ and -0.849$)$ in areas $\mathrm{B}$ and $\mathrm{C}$ were higher compared to area $\mathrm{A}$.

\section{Influence of Salinity on the Microplastic Abundance}

There was a large amount of surface runoff in the estuary and coastal areas to transport freshwater to the ocean, which created the low salinity of the seawater. Surface runoff was the most important way for microplastic to enter the ocean [27]. From the spatial distribution of microplastic abundance, the abundance value in the area closed to the land was higher than that in the area far from the land. This might be the reason why the abundance of microplastic was negatively correlated with seawater salinity in these areas.

Studies on the pollution of microplastic in Amoy Bay suggested that microplastic abundance would be significantly increased near the estuary due to 
the influence of saline wedge [28]. When the runoff in the river channel was strong and the tidal force was weak, freshwater was discharged into the sea due to the lower gravity density in the upper layer, and the brine with higher gravity density was located at the bottom layer and formed a saline wedge with the tide going up. During the wet season in summer, the fronts of freshwater and saline wedge moved away from the estuary. At this time, the salinity of seawater was low, and the strength of the saltwater wedge was strong. A large amount of microplastic particles were transported from the sediment and the bottom seawater to the surface layer, which increased microplastic abundance. This could also explain the distribution law of the high value of microplastic content mentioned above in the estuary area. This is of great significance for studied the influence mechanism of offshore temperature on the abundance of microplastic in Fig. 1.

Precipitation was an important factor affecting the salinity of seawater. It was confirmed that typhoon weather increased microplastic abundance in the seawater and sediments of the Sanggou Bay (area A) of the Yellow Sea in China [14]. The typhoon caused an increase in precipitation, which could transport microplastic from the surface of soil into the surface runoff. The microplastic was transported into the ocean by surface runoff. The increase of surface runoff and precipitation on the sea surface reduced the seawater salinity in offshore areas. It meant that the precipitation climate might be the cause of the negative correlation between microplastic abundance and seawater salinity.

Different types of microplastic particles have different densities. For example, low-density polyethylene (PE) particles generally floated on the surface of seawater, and polytetrafluoroethylene (PTFE) was generally suspended in seawater or deposited in sediment [29]. The surface seawater flowed fast, and microplastic particles in the surface of seawater diffused quickly. Seawater with high salinity had high density, which indicated that there were few suspended or precipitated microplastic particles. This might be one of the reasons why microplastic abundance in coastal areas was significantly higher than in marine areas far away from land (Fig. 1). The seawater in these areas evaporated quickly and the salinity was relatively high. Most of the microplastic particles were concentrated in the surface seawater and were quickly transported by ocean currents. The mechanism of the effect of the salinity in the surface seawater on the abundance of microplastic in the estuary area and the non-estuary area was different, but the effect on the negative correlation between the two was similar in the end.

The influence of salinity as an independent variable in the model was the lowest (shown in Fig. 3) due to the effects of salinity on microplastic abundance were all indirect. Precipitation, evaporation, seawater density, and other factors had a direct impact on microplastic abundance. These factors also affected salinity, caused by a relatively low degree of influence and correlation coefficient between salinity and microplastic abundance.

From the model results of the three areas, the proportion of sea temperature as an independent variable of the model were $27 \%, 29 \%$, and $24 \%$ (shown in Fig. 3). The effect of seawater temperature on microplastic abundance was much lower than the current velocity, which was similar to salinity. In general, there was a significant positive correlation between seawater temperature and salinity since the high temperature of seawater could dissolve more salt. The similarity of the correlation coefficient might be due to the significant positive correlation between seawater temperature and salinity.

\section{Influence of Current Velocity on the Microplastic Abundance}

The microplastic floating in the surface seawater would move with the ocean currents and eventually settle into the sediment or accumulate in the subtropical

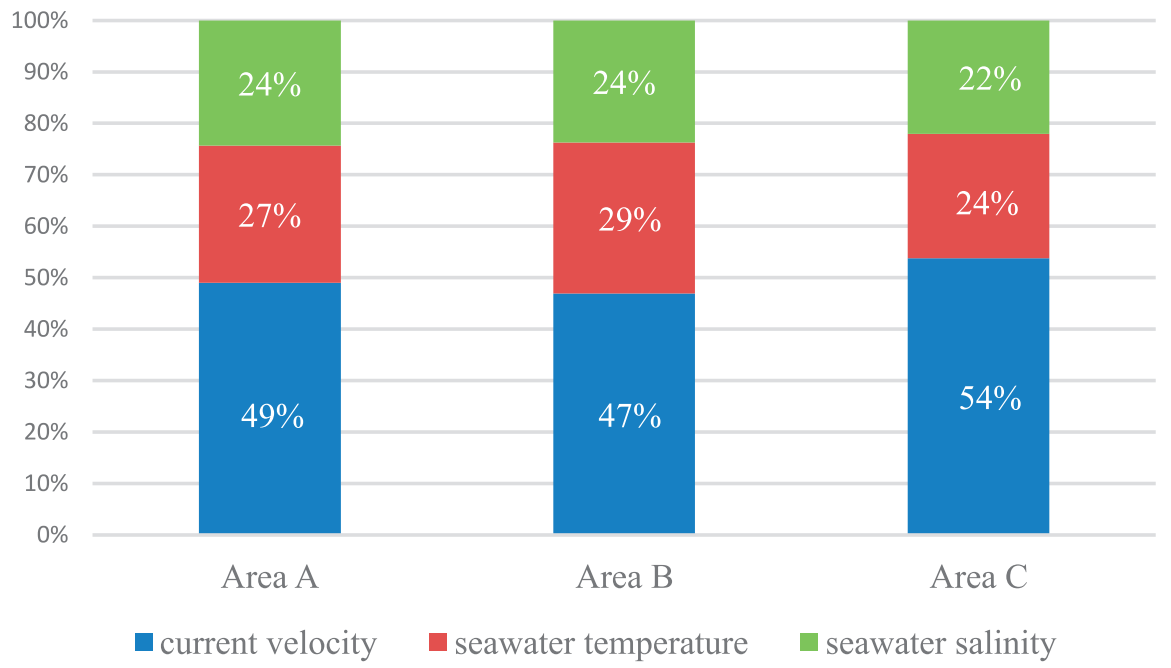

Fig. 3. Chart of the influence of the respective variables in the model. 
gyres [30]. The sampling time of the three areas was the season with the strong monsoon (shown in Table 1), and most of the ocean currents in the area belonged to wind-driven currents. The surface seawater of the wind-driven current moved fast, and the microplastic particles floating on the sea surface could be quickly diffused to other areas.

There were lots of surface runoffs along the coast of the ocean, and it was easy to form a density current near the estuary. Under the influence of density current, the surface seawater with a lower density near the estuary would move to the offshore area with higher density. As the density currents moved away from the estuary, the kinetic energy caused by the density difference was continuously consumed, and the velocity of the current would gradually decrease. Microplastic carried by current would accumulate in this area. This might be the reason for the high value of abundance of microplastic in similar locations such as DH34, DH15, OBT42, MTB33, LB01, WC02, and KB02 (Fig. 1).

In open seas, when the cold and warm currents converged, the kinetic energy canceled each other out, and the current velocity decreased. The difference in density caused the bottom seawater to rise, and the microplastic suspended in the middle seawater and the microplastic particles in the sediment moved to the surface of the seawater. This might be the reason for the high value of microplastic abundance at the sampling points of DH39 and DH32 (Fig. 1). These sampling points were located in the area where the Japanese warm current converged with the East China cold current [31].

In summary, when the ocean current was fast, the microplastic particles would be diffused, so it was difficult to accumulate in the area. The upwardly moved current could transport particles that were not easily detected to the surface and increased the detection value of microplastic abundance.

\section{Results of the Goodness of Fit $\left(R^{2}\right)$ of the Model}

The $\mathrm{R}^{2}$ values of the models in the three areas were shown in Table 6. The $\mathrm{R}^{2}$ values of area $\mathrm{B}(.973)$ and area $\mathrm{C}(.955)$ were higher than that of area $\mathrm{A}(.541)$. The independent variables, referenced by the model, could completely explain the differences in the dependent variables. It could be concluded that the temperature, salinity, and velocity of seawater all affect microplastic abundance in relatively closed seas.

Although the fitting effect of area A was significant, it was not as good as the fitting effect of areas B and C. The result meant that the factors, affected microplastic in open seas, were complex and diverse. Hydrological conditions such as temperature could only explain part of microplastic abundance.

Seawater temperature was mainly affected by cold and warm currents, seasons, and latitudes. In the open sea area, the difference in water temperature might also be different under the same latitude and seasonal conditions, because the effect of cold and warm currents on seawater temperature was relatively significant. Cold or warm currents also had a significant effect on seawater salinity. The salinity of a warm current was higher than that of a cold current at the same latitude [32]. The direction of the ocean current movement and the cold and warm current in open seas were affected by the monsoon and the Coriolis force, so it was seasonal. The source of microplastic particles in open seas was also relatively complex. In addition to terrestrial emissions in the area, ocean currents flowed through other areas would carry some particles into the area. The vertical movement of some ocean currents would transport the microplastic in the bottom sediment to the surface seawater. Although the use of statistical tools to select these basic hydrological conditions could prove that they had a significant impact on microplastic abundance, the introduction of more influencing factors as model-independent variables could make the goodness of the model better.

Relatively closed sea areas, such as straits or bays, had greater correlations among the influencing factors. These areas were rarely affected by cold and warm currents, and the temperature of seawater depended mainly on the season and latitude. Due to the relatively closed terrain, the salinity of seawater depended on runoff and evaporation and had regular seasonal characteristics. The direction of ocean currents in these areas was usually fixed, due to the difference in the salinity and the height of the sea surface inside and outside the area to form a density current or a compensation current. It meant that it was easier to establish the ideal goodness of fit by establishing mathematical models in relatively closed sea areas.

The analysis results of the model's VIF could also explain the reason for this difference (Table 4). VIF was a measure of the multicollinearity of the explanatory variables of the linear regression model. The larger value of VIF, the more accurate or highly correlated the variables were. Area A was an open sea area, and the VIF value (1.120) was lower than the relatively closed areas B and C (5.379 and 4.257). The results showed that the independent variables introduced in the process of constructing the area A model were relatively independent. This independence might be due to there were many factors affected the dependent variable (microplastic abundance), and it was difficult to reflect the influence relationship between the independent variables in the model. Independent variables were relatively independent due to the influence of other factors, not introduced into the model.

\section{Influence of Other Factors}

The physical shape of the microplastic particles had a significant effect on microplastic abundances in the area. Different shapes of particles had different settling velocity [33]. Under laboratory conditions, the settling 


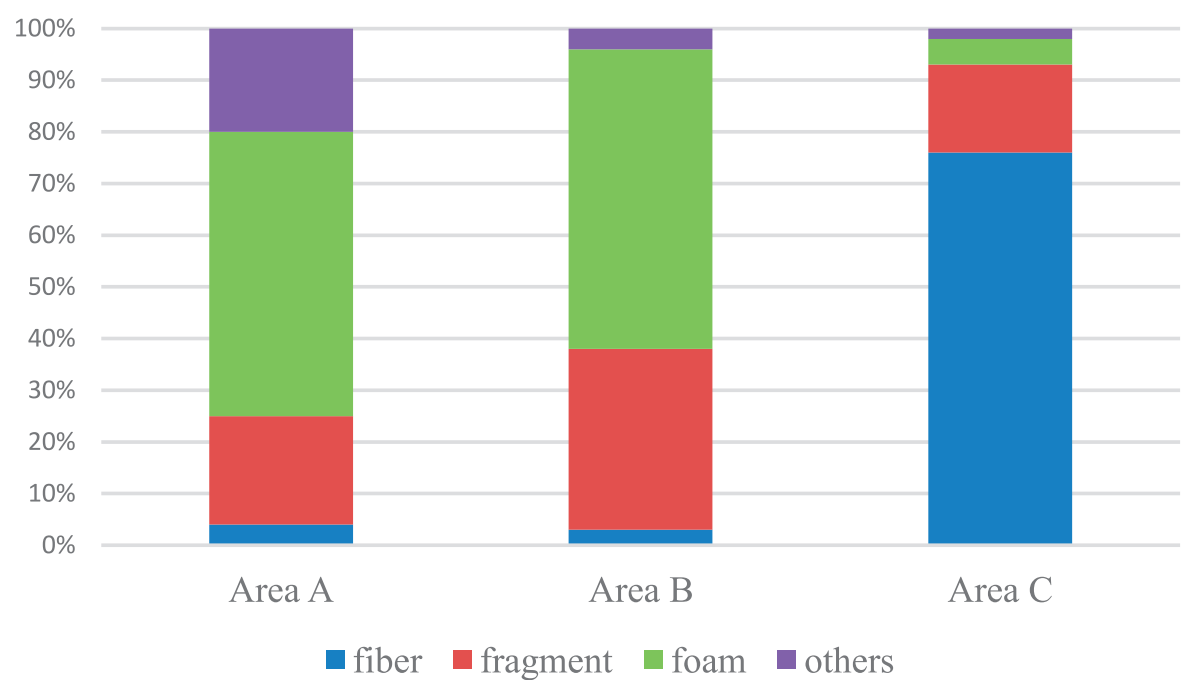

Fig. 4. The distribution ratio of the shape of the microplastic particles in the three areas. Blue indicated fiber; orange indicated fragment; gray indicated foam; yellow indicated others. Note: The distribution ratio of the shape of the microplastic particles in the three areas. Blue indicated fiber; orange indicated fragment; gray indicated foam; yellow indicated others.

velocity of cylindrical or spherical debris particles was faster, and the settling velocity of fibrous strip or filmlike fragments was relatively slow. Foamy fragments were difficult to deposit due to their loose physical structure [34].

The proportion distribution of microplastic shapes in areas A and B was similar, and foam was the main shape with the largest number. The fibrous microplastic in area $\mathrm{C}$ was the most important shape (Fig. 4). Area A was located on the eastern coast of China, and Area B was located on the island of East Java, Indonesia. Both areas were densely populated. Production activities were dominated by labor-intensive industries. The main sources of foam microplastic were pollution emissions from industrial production and foam floated in fisheries [35]. This explained that the proportion of foam microplastic in these two areas was large.

Area C was located in Tampa Bay, Florida, USA. The $19^{\text {th }}$ largest urban agglomeration in the United States was located here. The area was densely populated and had a high level of urbanization. The industry was dominated by electronics and light industries. The microplastic particles in this area were mainly fiber. The main sources of fiber microplastic were light industrial production and synthetic fiber fabrics [36]. The industrial structure and high urbanization rate in this area resulted in large amounts of fiber microplastic discharged into the ocean.

Foam microplastic could accumulate in the surface seawater for a long time due to its loose physical structure. It meant that it was more susceptible to ocean currents and to transport to other areas. Foam microplastic-based areas were more likely to form the high abundance in areas where ocean currents converged (Fig. 1). The distribution of the area $\mathrm{C}$ dominated by fiber microplastic was more even. It was caused by that the physical structure of the fibrous particles was more stable, the velocity was relatively slow during the current movement, and the sedimentation velocity was relatively fast.

From the analysis of the proportion of the influencing factors of the model, the influence of the current velocities of the model of areas A and B were similar (49\% and $47 \%$ ). The shape of the main microplastic fragments in these two areas was foam. Area C (54\%) was mainly fibrous fragments (Fig. 4). The results showed that the shape and spatial distribution of microplastic fragments in the area would be significantly affected when the current velocity had a greater impact on the microplastic in the area.

In summary, when the shape of microplastic particles in an area was dominated by a fast-settling velocity, microplastic abundance in this area was relatively low and the distribution was relatively concentrated. To a certain extent, the hydrological conditions could affect the accumulation of the microplastic fragments with different settling velocity and physical shape.

\section{Conclusions}

The purpose of this work was to collect microplastic abundance, hydrological data and establish mathematical models for analyzing the influence of temperature, salinity, and current velocity on microplastic abundance by using statistical tools. The model built in the semienclosed sea area was better than in the open sea area, which meant that building models in open seas might need to refer to more influencing factors. The model results showed that these three influencing factors had a significant negative correlation with abundance. In addition, the hydrological conditions could also certainly affect the accumulation of the microplastic 
fragments with different settling velocity and physical shape.

\section{Acknowledgments}

This work was supported by the National Natural Science Foundation of China (41877364 and 21707017) and the Jilin Province Science and Technology Development Projects (20180520079JH and 20200301012RQ).

\section{Conflict of Interest}

The authors declare no conflict of interest.

\section{References}

1. CARPENTER E.J., ANDERSON S.J., HARVEY G.R., MIKLAS H.P., PECK B.B. Polystyrene spherules in coastal water. Science 178, 749, 1972.

2. CARPENTER E.J., SMITH K.L. Plastics on the Sargasso Sea surface. Science 175, 1240, 1972.

3. COLTON J.B., BURNS B.R., KNAPP F.D. Plastic particles in surface waters of the northwestern Atlantic. Science 185, 491, 1974.

4. THOMPSON R.C., OLSEN Y., MITCHELL R.P., DAVIS A., ROWLAND S.J., JOHN A.W.G., MCGONIGLE D., RUSSELL A.E. Lost at sea: Where is all the plastic? Science 304, 838, 2004.

5. BARNES D.K.A., GALGANI F., THOMPSON R.C., BARLAZ M. Accumulation and Fragmentation of Plastic Debris in Global Environments. Phil. Trans. R. Soc. B. 364, 1985, 2009.

6. WRIGHT S.L., THOMPSON R.C., GALLOWAY T.S. The physical impacts of microplastics on marine organisms: A review. Environ. Pollut. 178, 483, 2013.

7. KANHAI L.D.K., GÅRDFELDT K., LYASHEVSKA O., HASSELLÖV M., THOMPSON R.C., O'CONNOR I. Microplastics in sub-surface waters of the Arctic Central Basin. Mar. Pollut. Bull. 130, 8, 2018.

8. KELLY A., LANNUZEL D., RODEMANN T., MEINERS K.M., AUMAN H.J. Microplastic contamination in east Antarctic sea ice. Mar. Pollut. Bull. 154, 111, 2020.

9. SUTTON R., MASON S.A., STANEK S.K., NORTON E.W., WREN I.F., BOX C. Microplastic contamination in the San Francisco Bay, California, USA. Mar. Pollut. Bull. 109, 230, 2016.

10. ZHAO J.M., RAN W., TENG J., LIU Y.L., LIU H., YIN X.N., CAO R.W., WANG Q. Microplastic pollution in sediments from the Bohai Sea and the Yellow Sea, China. Sci. Total Environ. 640-641, 637, 2018.

11. DESFORGES J.P.W., GALBRAITH M., DANGERFIELD N., ROSS P.S. Widespread distribution of microplastics in subsurface seawater in the NE Pacific Ocean. Mar. Pollut. Bull. 79, 94, 2014.

12. JAMBECK J.R., GEYER R., WILCOX C., SIEGLER T.R., PERRYMAN M., ANDRADY A., NARAYAN R., LAW K.L. Plastic waste inputs from land into the ocean. Science 347, 768, 2015.
13. CARR S.A., LIU J., TESORO A.G. Transport and fate of microplastic particles in wastewater treatment plants. Water Res. 91, 174, 2016.

14. WANG J., LU L., WANG M.X., JIANG T., LIU X.S., RU S.G. Typhoons increase the abundance of microplastics in the marine environment and cultured organisms: A case study in Sanggou Bay, China. Sci. Total Environ. 667, 1, 2019.

15. CHAE Y., KIM D., AN Y.J. Effects of micro-sized polyethylene spheres on the marine microalga Dunaliella salina: Focusing on the algal cell to plastic particle size ratio. Aquat. Toxicol. 216, 105296, 2019.

16. JIANG Y., YANG F., ZHAO Y.A., WANG J. Greenland sea gyre increases microplastic pollution in the surface waters of the Nordic Seas. Sci. Total Environ. 712, 136484, 2020.

17. LI J.N., LUSHER A.L., ROTCHELL J.M., DEUDERO S., TURRA A., BRÅTE I.L.N., SUN C.J., SHAHADAT H.M., LI Q.P., KOLANDHASAMY P., SHI H.H. Using mussel as a global bioindicator of coastal microplastic pollution. Environ. Pollut. 224, 522-533, 2019.

18. MARTINEZ E., MAAMAATUAIAHUTAPU K., TAILLANDIER V. Floating marine debris surface drift: Convergence and accumulation toward the South Pacific subtropical gyre. Mar. Pollut. Bull. 58, 1347, 2009.

19. MU J.I., ZHANG S.F., QU L., JIN F., FANG C., MA X.D., ZHANG W.W., WANG J.Y. Microplastics abundance and characteristics in surface waters from the Northwest Pacific, the Bering Sea, and the Chukchi Sea. Mar. Pollut. Bull. 143, 58, 2019.

20. LIU T., SUN X.X., ZHU M.L., LIANG J.H., ZHAO Y.F. Distribution and composition of microplastics in the surface water of the east China sea. Oceanologia Et Limnologia Sinica. 49, 62, 2018.

21. CORDOVA M.R., PURWIYANTO A.I.S., SUTEJA Y. Abundance and characteristics of microplastics in the northern coastal waters of Surabaya, Indonesia. Mar. Pollut. Bull. 142, 183, 2019.

22. MCEACHERN K., ALEGRIA H., KALAGHER A.L., HANSEN C., MORRISON S., HASTINGS D. Microplastics in Tampa Bay, Florida: Abundance and variability in estuarine waters and sediments. Mar. Pollut. Bull. 148, 97, 2019.

23. LI Z., LIU Z.H., LU S. Global Argo data fast receiving and postquality-control system. IOP Conference Series: Earth and Environmental Science, 2019.

24. Global Forecasting System (GFS). Global Marine Hydrological Information Database. https:/earth. nullschool.net/, 2019.

25. FARRAR D.E., GLAUBER R.R. Multicollinearity in regression analysis; the problem revisited. The Review of Economics and Statistics. 1, 1967.

26. VEERASINGAM S., SAHA M., SUNEEL V., VETHAMONY P., RODRIGUES A.C., BHATTACHARYYA S., NAIK B.G. Characteristics, seasonal distribution and surface degradation features of microplastic pellets along the Goa coast, India. Chemosphere 159, 496, 2016

27. WALDSCHLÄGER K., LECHTHALER S., STAUCH G., SCHÜTTRUMPF H. The way of microplastic through the environment-Application of the source-pathway-receptor model (review). Sci. Total Environ. 713, 136584, 2020.

28. LONG Z.X., PAN Z., WANG W.L., REN J.Y., YU X.G., LIN L.Y., LIN H., CHEN H.Z., JIN X.L. Microplastic 
abundance, characteristics, and removal in wastewater treatment plants in a coastal city of China. Water Res. 155, 255, 2019.

29. GARTH A.C., CHRISTOPHER P.M., HELEN G.S.J., STEPHEN C.G., PETER R.S., JOHN D.F., SARAH D.E. Size and shape matter: A preliminary analysis of microplastic sampling technique in seawater studies with implications for ecological risk assessment. Sci. Total Environ. 667, 124, 2019.

30. BRACH L., DEIXONNE P., BERNARD M.F., DURAND E., DESJEAN M.C., PEREZ E., SEBILLE E.V., HALLE A.T. Anticyclonic eddies increase accumulation of microplastic in the North Atlantic subtropical gyre. Mar. Pollut. Bull. 126, 191, 2018.

31. WAGAWA T., KURODA H., ITO S.I., KAKEHI S., YAMANOME T., TANAKA K., ENDOH Y., KAGA S. Variability in water properties and predictability of sea surface temperature along Sanriku coast, Japan. Cont. Shelf R. 103, 12, 2015.
32. WELDEAB S., SCHNEIDER R.R., KÖLLING M. Deglacial sea surface temperature and salinity increase in the western tropical Atlantic in synchrony with high latitude climate instabilities. Earth Planet. Sci. Lett. 241, 699, 2005.

33. KHATMULLINA L., ISACHENKO I. Settling velocity of microplastic particles of regular shapes. Mar. Pollut. Bull. 114, 871, 2016.

34. TANAKA K., TAKADA H. Microplastic fragments and microbeads in digestive tracts of planktivorous fish from urban coastal waters. Sci. Rep. 6, 34351, 2016.

35. ZHOU Q., ZHANG H.B., FU C.C., ZHOU Y., DAI Z.F., LI Y., TU C., LUO Y.M. The distribution and morphology of microplastics in coastal soils adjacent to the Bohai Sea and the Yellow Sea. Geoderma 322, 201, 2018.

36. CAI Y., MITRANO D.M., HEUBERGER M., HUFENUS R., NOWACK B. The origin of microplastic fiber in polyester textiles: The textile production process matters. J. Clean. Prod. 267, 121970, 2020. 